\section{Case Reports in Ophthalmology}

Case Rep Ophthalmol 2017;8:401-405

DOI: $10.1159 / 000478721$ Publisned onlıne: July 25, 2017
(C) 2017 The Author(s)

Published by S. Karger AG, Basel www.karger.com/cop

This article is licensed under the Creative Commons Attribution-NonCommercial 4.0 International License (CC BY-NC) (http://www.karger.com/Services/OpenAccessLicense). Usage and distribution for commercial purposes requires written permission.

\title{
Pseudomonas Scleritis following Pterygium Excision
}

\author{
Winai Chaidaroon Sumet Supalaset \\ Department of Ophthalmology, Faculty of Medicine, Chiang Mai University, \\ Chiang Mai, Thailand
}

\section{Keywords}

Pseudomonas aeruginosa $\cdot$ Infectious scleritis · Surgical debridement

\begin{abstract}
Purpose: The aim of this case report was to describe a patient who presented with Pseudomonas scleritis after pterygium excision. The study was conducted at the Department of Ophthalmology, Faculty of Medicine, Chiang Mai University in Chiang Mai, Thailand. Methods: The record of a patient who was diagnosed as Pseudomonas scleritis after pterygium excision was retrospectively reviewed for history, clinical characteristics, laboratory findings, treatments, and outcomes. Results: We described a 66-year-old male patient with a history of pterygium excision in his right eye 10 years ago, he presented with infectious scleritis. Scleral thinning, tissue necrosis, and overlying calcified plaque were found. The culture of scleral scraping revealed Pseudomonas aeruginosa. Topical fortified amikacin $(20 \mathrm{mg} / \mathrm{mL})$ and intravenous ceftazidime were started. Urgent surgical debridement of scleral infiltrates and irrigation of necrotic sclera and surrounding conjunctiva with fortified amikacin $(20 \mathrm{mg} / \mathrm{mL})$ were performed. After 2 weeks of treatment, scleral thinning and inflammation decreased, and the best-corrected visual acuity improved from 6/24 to 6/9. Fortified amikacin eye drops $(20 \mathrm{mg} / \mathrm{mL}$ ) were continued until the fourth week, with no scleral thinning seen. Conclusions: $P$. aeruginosa is a virulent organism that causes infectious scleritis complicated by melting and necrotizing of the sclera. This report emphasized that early recognition, intensive antimicrobial treatment, and surgical debridement can prevent morbidity related to this Pseudomonas infection.




\section{Case Reports in Ophthalmology}

\section{Introduction}

Scleritis has been classified as infectious scleritis and immune-mediated scleritis. Infectious scleritis is rare and typically occurs following trauma or surgery. The most common surgical cause of infectious scleritis is a previous pterygium excision [1,2] with other causes from prior cataract surgery [1], prior strabismus surgery [3], and prior trabeculectomy [4]. The most common causative pathogen of infectious scleritis is Pseudomonas aeruginosa [2, 5-7], a virulent organism that can produce protease. Previous studies have reported various treatments of infectious Pseudomonas scleritis with topical antibiotic eye drops only [8], adjunctive oral imipenem [9], adjunctive intravenous ceftazidime and aminoglycoside [10], adjunctive surgical debridement [11], adjunctive cryotherapy [12], and autologous perichondrium graft [13]. This study demonstrated another option of treatment in a patient with infectious Pseudomonas scleritis.

\section{Case History}

A 66-year-old Thai male patient presented with a history of right eye pain and redness with mucopurulent discharge for 10 days. He had a pterygium excision in his right eye 10 years ago but no history of eye injury or underlying autoimmune disease. A secondary hospital referred him to our tertiary hospital after 1 week of treatment for necrotizing scleritis with gatifloxacin ophthalmic solution hourly in his right eye and ciprofloxacin (500 mg) 1 tablet twice daily, with no improvement of his lesion.

At his first visit, the best-corrected visual acuity (BCVA) was 6/24, OD and 6/6, OS. Slitlamp examination revealed marked injection of the conjunctiva, mucopurulent discharge, and scleral thinning surrounded by edematous tissue in the temporal sclera near the limbus (Fig. 1a). The patient was admitted and was treated as infectious necrotizing scleritis. Scleral scraping was performed, and the scleral tissue was sent for bacterial and fungal culture, $\mathrm{KOH}$ examination, and gram staining. The result of bacterial culture showed P. aeruginosa (Fig. 1b), which was sensitive to amikacin, colistin, ceftazidime, imipenem, meropenem, ciprofloxacin, and levofloxacin. Treatment was started with fortified amikacin $(20 \mathrm{mg} / \mathrm{mL})$ hourly, acetylcysteine eye drops 4 times daily, intravenous ceftazidime $1 \mathrm{gm}$ every $8 \mathrm{~h}$, vitamin C (500 mg) 1 tablet twice daily, and doxycycline $(100 \mathrm{mg}) 1$ tablet twice daily. Urgent surgical debridement of superficial necrotic tissue and all discharge was performed after 4 days of nonresponsive medical treatment. After 2 weeks of medication, the BCVA improved to 6/9 in the right eye with decreased scleral thinning, ciliary injection, and mucopurulent discharge (Fig. 1c). Intravenous ceftazidime was discontinued, and fortified amikacin $(20 \mathrm{mg} / \mathrm{mL})$ was decreased to every $2 \mathrm{~h}$, while other medications were continued. After 3 weeks of intensive treatment, fortified amikacin $(20 \mathrm{mg} / \mathrm{mL})$ was decreased to every $4 \mathrm{~h}$, and the other medications were maintained. Fortified amikacin $(20 \mathrm{mg} / \mathrm{mL})$ was discontinued after 1 month and replaced with levofloxacin eye drops. At 2 weeks of follow-up, the BCVA was 6/9 in the right eye. No scleral thinning was seen (Fig. 1d).

\section{Discussion}

The cause of scleritis in this case was prior pterygium excision, which has been reported as the most common surgical etiology for infectious scleritis [1, 2]. The causative organism 
Case Reports in
Ophthalmology

was $P$. aeruginosa, well known as a virulent organism that produces protease and causes melting and perforation of the sclera. It also has an ability to form a biofilm complex, which impedes its clearance by the immune-defense mechanism [14]. Various methods of treatment in patients with infectious Pseudomonas scleritis, including topical antibiotic eye drops only [8], adjunctive oral imipenem [9], adjunctive intravenous ceftazidime and aminoglycoside [10], adjunctive surgical debridement [11], adjunctive cryotherapy [12], and autologous perichondrium graft [13] have been reported in previous studies. A study by Codère et al. [8] showed failure of medical treatment with topical antibiotic eye drops only. After being treated with topical fortified amikacin $(20 \mathrm{mg} / \mathrm{mL})$ hourly and intravenous ceftazidime $1 \mathrm{mg}$ every $8 \mathrm{~h}$ for 4 days, the scleritis seemed to be nonresponsive to treatment. This may be explained by the poor scleral penetration of topical antibiotic eye drops. Therefore, urgent surgical debridement and wound irrigation with fortified amikacin $(20 \mathrm{mg} / \mathrm{mL})$ was performed, and all necrotic tissue and discharge were removed to promote direct scleral penetration of antibiotics. We expected the protease and biofilm had also been washed out. This study found that early surgical debridement and wound irrigation with fortified amikacin $(20 \mathrm{mg} / \mathrm{mL}$ ) could expedite wound healing. Topical steroid was not used in this case because mixed organisms or infection combined with fungus had been reported in previous studies $[1,15]$. Furthermore, cryotherapy was not performed in this case because of inadequate evidence proven in humans [12].

\section{Conclusions}

P. aeruginosa is a virulent organism that can cause infectious scleritis complicated with melting and perforation of the sclera. This study emphasized that early surgical debridement and wound irrigation with antibiotics is an effective treatment. Prompt diagnosis and vigorous surgical and medical treatment can prevent blindness in such cases.

\section{Acknowledgement}

The authors gratefully acknowledge Dr. Atchareeya Wiwatwongwana, MD, for reviewing the English manuscript.

\section{Statement of Ethics}

The authors have no ethical conflicts to disclose.

\section{Disclosure Statement}

None of the authors has any conflicts of interest concerning the case report. 
References

1 Jain V, Garg P, Sharma S: Microbial scleritis - experience from a developing country. Eye (Lond) 2009;23:255-261.

- Ho YF, Yeh LK, Tan HY, Chen HC, Chen YF, Lin HC, Chen SY, Hui-Kang D, Hsiao CH: Infectious scleritis in Taiwan - a 10-year review in a tertiary-care hospital. Cornea 2014;33:838-843.

-3 Chao DL, Albini TA, McKeown CA, Cavuoto KM: Infectious Pseudomonas scleritis after strabismus surgery. J AAPOS 2013;17:423-425.

-4 Lin AP, Chung JE, Zhang KS, Chang MM, Orengo-Nania S, Gross RL, Chang PT: Outcomes of surgical bleb revision for late-onset bleb leaks after trabeculectomy. J Glaucoma 2013;22:21-25.

5 Hsiao CH, Chen JJ, Huang SC, Ma HK, Chen PY, Tsai RJ: Intrascleral dissemination of infectious scleritis following pterygium excision. Br J Ophthalmol 1998;82:29-34.

-6 Hodson KL, Galor A, Karp CL, Davis JL, Albini TA, Perez VL, Miller D, Forster RK: Epidemiology and visual outcomes in patients with infectious scleritis. Cornea 2013;32:466-472.

-7 Lin CP, Shih MH, Tsai MC: Clinical experiences of infectious scleral ulceration: a complication of pterygium operation. Br J Ophthalmol 1997;81:980-983.

-8 Codère F, Brownstein S, Jackson WB: Pseudomonas aeruginosa scleritis. Am J Ophthalmol 1981;91:706710.

-9 Moreno Honrado M, del Campo Z, Buil JA: A case of necrotizing scleritis resulting from Pseudomonas aeruginosa. Cornea 2009;28:1065-1066.

10 Helm CJ, Holland GN, Webster RG Jr, Maloney RK, Mondino BJ: Combination intravenous ceftazidime and aminoglycosides in the treatment of pseudomonal scleritis. Ophthalmology 1997;104:838-843.

11 Huang SC, Lai HC, Lai IC: The treatment of Pseudomonas keratoscleritis after pterygium excision. Cornea 1999;18:608-611.

12 Eiferman RA: Cryotherapy of Pseudomonas keratitis and scleritis. Arch Ophthalmol 1979;97:16371639.

13 Yoo WS, Kim CR, Kim BJ, Ahn SK, Seo SW, Yoo JM, Kim SJ: Successful treatment of infectious scleritis by Pseudomonas aeruginosa with autologous perichondrium graft of conchal cartilage. Yonsei Med J 2015;56:1738-1741.

14 Rasamiravaka T, Labtani Q Duez P, El Jaziri M: The formation of biofilms by Pseudomonas aeruginosa: a review of the natural and synthetic compounds interfering with control mechanisms. Biomed Res Int 2015;2015:759348.

15 Abbey AM, Shah NV, Forster RK, Suh LH: Infectious Pseudomonas and bipolaris scleritis following history of pterygium surgery. Indian J Ophthalmol 2016;64:674-676. 

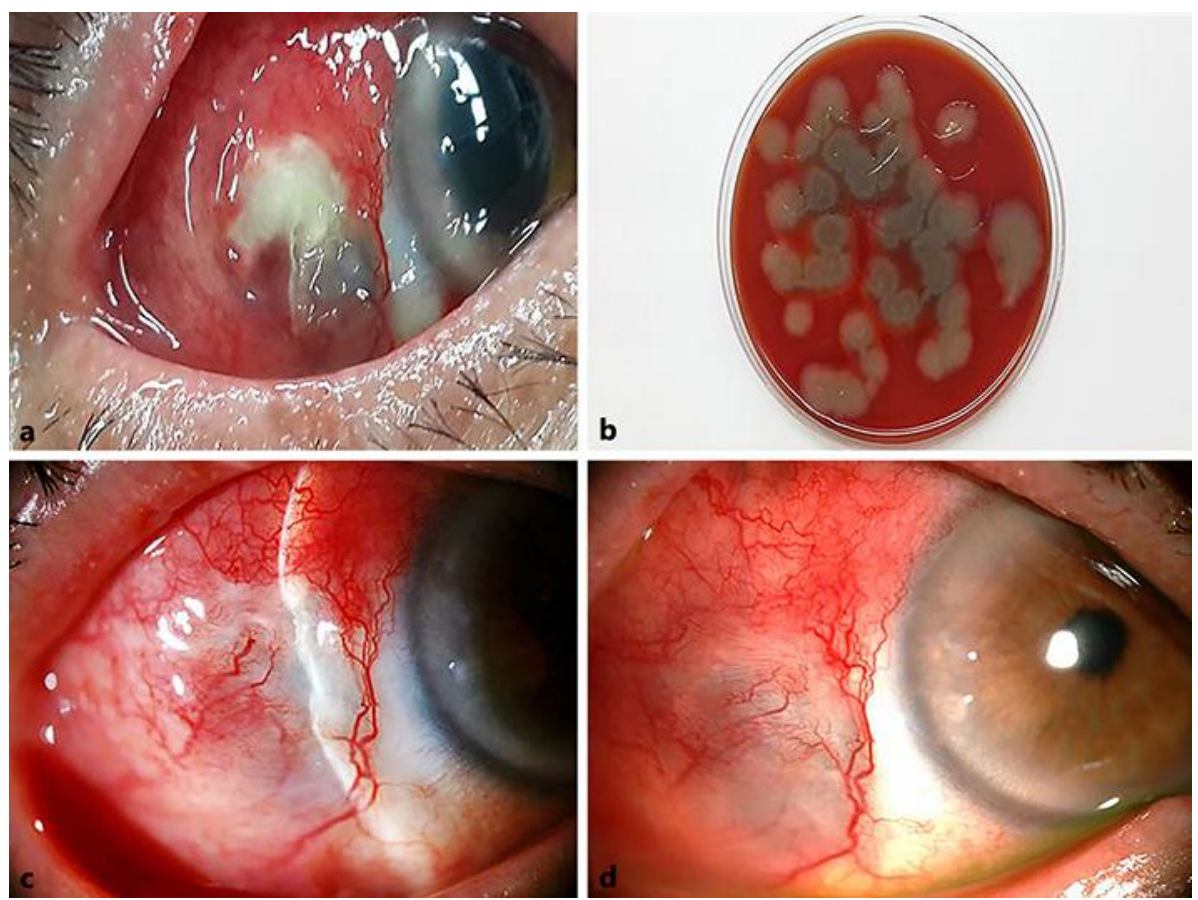

Fig. 1. Photographs of the right eye before and after treatment and colonies of Pseudomonas aeruginosa. a Marked ciliary injection, scleral thinning with necrotic tissue, and mucopurulent discharge are noted in the right eye at the first-visit eye examination. $\mathbf{b}$ Colonies of $P$. aeruginosa are demonstrated on blood agar. c After 2 weeks of medication, a decreased area of scleral thinning is seen. $\mathbf{d}$ Re-epithelialization without corneal involvement is shown at the first follow-up visit. 